Florida International University FIU Digital Commons

3-15-1995

\title{
The effect of age of analyst and reform of data on the results of focus groups with older persons
}

Marian Cherie Clark

Florida International University

DOI: $10.25148 /$ etd.FI14060843

Follow this and additional works at: https://digitalcommons.fiu.edu/etd

Part of the Psychology Commons

\section{Recommended Citation}

Clark, Marian Cherie, "The effect of age of analyst and reform of data on the results of focus groups with older persons" (1995). FIU Electronic Theses and Dissertations. 2373.

https://digitalcommons.fiu.edu/etd/2373 
FLORIDA INTERNATIONAL UNIVERSITY

Miami, Florida

THE EFFECT OF AGE OF ANALYST AND FORM OF DATA

ON THE RESULTS OF FOCUS GROUPS WITH OLDER PERSONS

A dissertation submitted in partial satisfaction of the requirements for the degree of DOCTOR OF PHILOSOPHY

IN

PSYCHOLOGY

by

Marian Cherie Clark

1995 
To: Dean Arthur W. Herriott

College of Arts and Sciences

This dissertation, written by Marian Cherie Clark, and entitled The Efffect of Age of Analyst and Form of Data on the Results of Focus Groups with older Persons, having been approved in respect to style and intellectual content, is referred to you for judgement.

We have read this dissertation and recommend that it be approved.

William M. Kurtines

Scott L. Fraser

Hugh Gladwin

Mary J. Levitt, Major Professor

Date of Defense: March 15, 1995

The dissertation of Marian Cherie Clark is approved.

Dean Arthur W. Herriott

College of Arts and Sciences

Dean Richard L. Campbell

Division of Graduate Studies

Florida International University, 1995 
I dedicate this dissertation to Paul and Arlo. Support comes in many forms and you have given me all of these and more.

.... by our hearts, we are whole 
ACKNOWLEDGEMENTS

I wish to thank the members of my committee for their helpful comments and support. A special thanks is due my major professor, Dr. Mary Levitt, for her unfailing support from the very beginning. I could not have finished without her gentle encouragement and "long distance" assistance.

A special thank you goes to Jack zellner, the designer of the Comfortcare Bath system, a brilliant and caring man, and great fun at conventions. Many good people where I have worked over the years at Queens College, Davidson College, and the stein Gerontological Institute have all made the road a little smoother.

Friends both far and near, old and new have surprised me with a degree of support I could not ever imagine, and especially Tom Penge. You all have removed many of the bumps along the way.

I would also like to thank all of the wonderful young and old people who served as participants in the research. I have learned much from all of you and am richer for having met you.

Finally, to my first and constant reader and editor, my table maker, my unswerving pillar, my life partner, Paul Foos. You have made it all possible and, oh, so much more fun, to travel the roads of life - even those back roads! 


\section{ABSTRACT OF THE DISSERTATION}

\section{THE EFFECT OF AGE OF ANALYST AND FORM OF DATA ON THE RESULTS OF FOCUS GROUPS WITH OLDER PERSONS}

by

Marian Cherie clark

Florida International University, 1995

Miami, Florida

Professor Mary J. Levitt, Major Professor

Focus groups, a typical market research method used with young consumers, are currently being used with older consumers to identify the needs and desires of this potential market segment. Research suggests, however, that social interaction and risk taking behaviors may be different for older and younger persons. The current practice of using young persons to analyze and interpret the discussions of older focus group members may be a serious methodological error. To test this, twenty young men and women (age range 17-35), and twenty old men and women (age range 65-89) analyzed either videotapes or typed transcripts of focus group discussions held with older persons. It was hypothesized that older adults would analyze and interpret 
discussions of other older adults differently than would young persons and that videotapes would provide more information, most notably nonverbal cues, than would typed transcripts. However, results indicate that older and younger analysts did not categorize discussion components differently. Participants did not see, hear, or read different information based on age or form of discussion data used. For ratings of emotions expressed by focus group members and selecting quotes representing group discussions, videotaped discussions appeared to interfere with these tasks. Finally, significant age differences were found for recommendations for marketing the bath system discussed in the focus groups. Older persons were more likely than young persons to choose the two extremes of either marketing the bath with no changes or not putting it on the market at all. Results are discussed in terms of their implications for the conduct of focus groups with older adults, guidelines for the use of videotapes versus typed transcripts in focus group analysis, and the importance of hiring older persons to serve as both moderators and analysts of focus groups held with older adults. 


\section{TABLE OF CONTENTS}

SECTION

PAGE

I. Introduction $\ldots \ldots \ldots \ldots \ldots \ldots \ldots \ldots \ldots \ldots \ldots \ldots \ldots \ldots \ldots$

II. Literature Review $\ldots \ldots \ldots \ldots \ldots \ldots \ldots \ldots \ldots \ldots$

Marketing to older Consumers ........... 2

Review of Focus Group Research ......... 5

Age Differences in Group Interaction ....... 16

Analyst and Form of Data Predictions ....... 20

III. Methodology ........................ 23

Preliminary Focus Group Sessions ......... 23

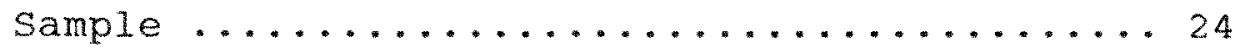

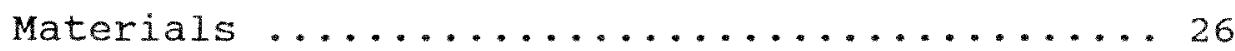

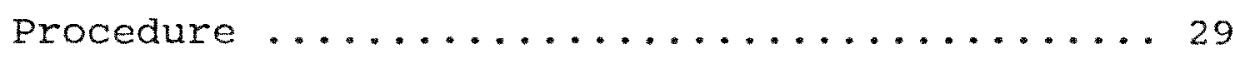

IV. Results ............................ 31

Discussion Categorization .............. 31

Informational and Socioemotional Ratings .... 34

Representative Comments .............. 35

Product Recommendations ............. 36

Reactions to Research process ......... 37

V. Discussion and Implications ............... 40

LIST OF REFERENCES $\ldots \ldots \ldots \ldots \ldots \ldots \ldots \ldots \ldots \ldots \ldots$

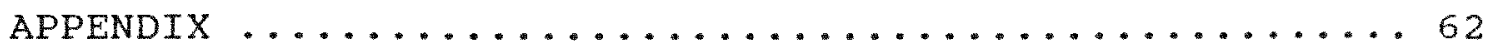




\section{LIST OF TABLES}

TABLE

PAGE

TABLE 1: Means and $\underline{E}$ values

for Discussion Categorization Analyses ........... 56

TABLE 2: Means and $\underline{F}$ values

for Transcript and Videotape Groups

on Informational Behavior Analyses ............ 58

TABLE 3: Means and $E$ values

for Age Groups on Informational

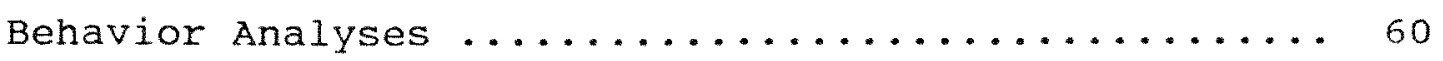

TABLE 4: Recommended Marketing strategies ........ 61 
The Effect of Age of Analyst and Form of Data on the Results of Focus Groups with Older Persons The population of America is aging. There are more individuals over the age of 65 than history has ever seen. In 1900 only one out of every 25 Americans was elderly. By 1986, one in eight people were 65 or older. The number of older adults increased almost tenfold (U.S. Senate Special Committee on Aging, 1987). This shift in demographics is expected to become even more dramatic in the next decades. It is expected that by the year 2010, one out of seven Americans will be over 65 years of age. By 2030, this percentage will swell to one in five (U.S. Senate special Committee on Aging, 1987). More people are living longer. In fact, the fastest growing segment of the older population consists of individuals over 85 years of age. By 2030, the current $1 \%$ of all Americans over the age of 85 is expected to grow to more than $5 \%$ (U.S. Senate Special committee on Aging, 1987).

Economics of aging present some interesting dichotomies. The median income of individuals 65 and older is significantly less than the income of all age groups over the age of 20 (Zopf, 1986). About 3.5 million elderly persons in 1985 were below the poverty line with another 2.3 million classified as "near poor" (U.S. Department of Health and Human Services, 1987). Contrast these statistics with the facts that the size of households and expenses are 
smaller for older persons and many people over 60 have accumulated significant resources including high home equity, pensions, and private retirement plan income. Consumer research suggests that people aged 50 and over hold one-half of the nation's discretionary income (Linden, 1986). So while there is no question that a significant number of this growing segment of the population have limited economic resources, it is equally evident that there exists a large number of older Americans in good economic conditions.

This last group, older people with disposable income, are of particular interest to marketers. The significant increase in the number of articles in business publications dealing with the older market attests to this interest. Information on consumer behavior of older adults is in demand (e.g., Kiley, 1988; Gilly \& Zeithmal, 1985). Advertisers are seeking data on the needs and interests of people over 65 (e.g., Stephens \& Warrens, 1983; Rossell, 1987: Greco, 1988). Marketers are attempting to identify what products might serve this older target market, (e.g., Bivens, 1988; Schneidman, 1988; Resener \& Prout, 1986). There is now a growing understanding of the diversity in the older population; all old people are not alike. The great interindividual differences among older persons are accepted as fact. However, from a business perspective, there is a strong need to identify similarities among at 
least subgroups of older people. Researchers have found it useful to think of chronological subgroups of older people. Marketers refer to this as market segmentation based on different needs, attitudes, or preferences. The young-old, typically considered to be those people aged 65-75, are fairly healthy and still very active. The middle-old group, persons aged 75-85, are still somewhat active and a little less healthy. In contrast, people 85 years of age and over, the old-old, tend to be frail and in need of assistance. In fact, by about the 9 th decade of life the chance of being physically disabled by illness and in need of some assistance with daily activities increases dramatically (U.S. Public Health Service, 1986). Given the diversity in the aging population and the increases in longevity, products geared to the needs of healthy young-older persons (e.g., cars, travel packages), the transitional middle-old (e.g., retirement housing, food and personal care products), and frail old-older persons (e.g., health care products) are being seriously considered. What is still lacking is knowledge about the needs, wants, and desires of older people.

In a review of marketing studies with persons 65 years of age and older, Mertz and Stephens (1986) offer some general marketing strategies based on studies of buying styles, product and service needs, and shopping behavior. For example, they suggest that businesses might effectively 
appeal to older adults by offering small trial-size packages based on findings that people over 65 have a strong economic value orientation and perceive trying new products as a risky venture. The National council on the Aging comissioned Louis Harris to conduct a nationwide in-depth exploration of attitudes, perceptions, feelings and facts about older adults (Harris \& Associates, 1981). This study provided marketers and product developers, among others, with a clear picture of the general concerns and interests of older adults. For example, economics and health issues were perceived by the elderly as salient problems (Harris \& Associates, 1981). However, these findings can provide only general directions. The heterogeneous nature of the elderly population precludes using such broad data to predict specific behavior in marketing. It is well accepted that older persons rarely, if ever, comprise a single market segment for any product or service (Torp, 1991).

If a company, or individual, intends to develop or market a product for a specific market, they must get much more detailed information about the needs and preferences of the target population. There are two primary methods used to obtain this detailed information. Survey research, including questionnaires and individual interviews, is often used to obtain consumer feedback and predict market acceptance. Another popular technique has become the preferred method to obtain consumer information by many 
marketers and advertisers (Coe \& MacLachlan, 1980), that is focus group research, also called in-depth group interviews. This method is currently being applied to a great variety of issues in marketing to the older population. Given the paucity of research on focus groups, in general, and none on the use of elderly people as group members, there may be some question regarding the validity of results emerging from these groups. The research proposed here is designed to investigate the use of focus group research with older adults in marketing applications.

\section{Review of Focus Group Research}

originally called focussed (sic) groups, or focused interviews, the focus group technique was established by Robert Merton in 1941 (Stewart \& Shamdasani, 1990). Group interviewing, according to Yoell (1979) was used in Freudian psychotherapy as part of the psychoanalytic process. Earlier, a French physician reported using the group approach in medical treatment in 1913 (Yoell, 1979). Merton's focussed groups were used not for treatment but rather to examine the persuasiveness of wartime propaganda (Morgan, 1988). Others interested in using the group interview technique to elicit information from consumers modified Merton's original methodology and the focus group has evolved to become a well accepted and leading tool for applied social scientists, and those who work in marketing, advertising, program evaluation, public policy, and 
communication (Stewart and Shamdasani, 1990). The focus group technique is the most frequently used of the group techniques employed in business applications.

There is no one accepted definition of focus groups acceptable to all key professionals in the marketing and marketing research community. Stewart and Shamdasani (1990) describe the focus group technique as one seeking detailed information on a limited number of issues from a number of individuals interacting with a common interest. Greenbaum (1988) reports that it is generally recognized that focus groups contain the following four components: 1) several respondents participate simultaneously in the group discussion process; 2) group members are encouraged to interact with one another; 3) a trained moderator leads the group discussion and keeps respondents to the topics necessary to achieve the data-gathering objectives; and 4) focus group discussion follows a prepared outline that serves as a guide to the moderator to focus the information collection process.

One reason for the popularity of focus groups is their flexibility, Focus groups have been used for generating hypotheses; exploring opinions, attitudes, and attributes; testing new products and ideas; evaluating media programs and identifying and pretesting questionnaire items (Bellenger, Bernhardt, \& Goldstucker, 1976). Regardless of use of the technique, the effectiveness of focus groups 
depends on the group discussion (Greenbaum, 1988; Krueger, 1994; Morgan, 1988; Stewart \& Shamdasani, 1990; Templeton, 1987). This is a critical aspect of the focus group technique, understood and accepted by all who advocate its use. Greenbaum (1988) offers that the basic philosophy behind the focus group methodology draws on theory and principles of group dynamics, and holds that the group process results in the generation of more and more useful information than would otherwise be available. He suggests that this occurs because: 1) most people feel more comfortable talking about issues in a group than by themselves, 2) the interaction and feelings expressed in a group act to stimulate others to be more talkative; and 3) the dynamics of the group offer insight into individual acceptance versus conformity with peers regarding a concept or idea. Fern (1982a) examined several small group process theories to generate a general theory of the role of social impact in the focus group process. Specifically, he suggests that focus groups are effective in eliciting detailed discussions due to the effects of deindividuation, social facilitation, diffusion of responsibility, and social impact. Each of these processes works to a greater or lesser extent based on the use and conduct of the focus group.

There is considerable agreement that groups produce high quality data, although research is lacking to 
substantiate this claim (Yoell, 1979). In fact, Fern (1982b) conducted a study in which he found that, compared to focus groups, individual interviews generated more ideas and more ideas rated "good" for the purpose of the research. However, number of ideas is a variable relevant to only some uses of focus group research and the use of a single rating for quality of ideas must be taken into account. Goldman (1962) reported study results in which focus groups provided more information that was qualitatively different from that obtained by summing results of individual interviews. Hess (1968) compared the output from summed individual interviews and focus groups and found that the latter produced a wider range of information, insight, and ideas than can be obtained from individuals. Despite the limited research, and Fern's findings notwithstanding, most proponents of focus groups continue to stress the qualitative superiority of data generated using this technique over other methods with similar objectives.

Examining the basic handbooks, texts, and guides to conducting focus group research (Greenbaum, 1988; Morgan, 1988; Stewart \& Shamaasani, 1990; Templeton, 1987) there is considerable agreement regarding accepted practice for the conduct of group interviews. There are some disagreements regarding various aspects but, by and large, these dissensions are not strong. Focus groups are typically conducted with 8-12 participants. While there has been some 
disagreement and discussion of the effects of size of the group on discussion output, few empirical data exist. In a review of the literature, Fern (1982b) found little agreement as to optimal size for focus groups. In his own research, he found that 8 member focus groups generated more ideas than 4 member focus groups. All guides to conducting focus groups recommend 8-12 participants, reporting that fewer than 8 makes for a dull discussion, whereas more than 12 prove difficult for a moderator to handle and maintain group discussion (e.g., Greenbaum, 1988).

Most focus group guides recommend that members of the group be strangers or unrelated. Justification for this position comes from group process theory that holds that familiarity inhibits disclosure in group discussion (Krueger, 1994). What little research exists is equivocal in its findings. In his research, Fern (1982b) found a small but nonsignificant difference in the number of ideas generated favoring groups with strangers over groups made up of acquaintances. Fern (1982b) noted that focus groups are most often conducted (and his were no exception) with a waiting period and a warm-up session in which group members have a chance to become familiar with one another before the group discussion begins. Nelson and Frontczak (1988) examined the effects of acquaintanceship on idea quality and quantity using groups made up of couples, acquaintances, and strangers. These authors found small effects favoring 
strangers for idea quantity only. They conclude that the effects of acquaintanceship were not great enough to justify using strangers only in focus groups. There is substantial agreement that groups should be made up of people with similar interests in order to facilitate discussion (stewart \& Shamdasani, 1990). Homogeneity is often achieved as a matter of course given that focus group participants are usually recruited to represent specific population segments.

Moderator characteristics and their effects on the output of focus groups have been debated for many years (Stewart \& Shamdasani, 1990). The general consensus is that a good moderator is one who has been well trained to conduct focus groups and who is friendly, knowledgeable, able to make quick decisions, is a good listener, shows empathy, and is insightful about people (Greenbaum, 1988). Stewart and Shamdasani (1990) draw on literature on leadership and suggest that a good moderator is the result of individual characteristics, such as personality and intelligence, and interpersonal processes, such as group cohesiveness. Fern (1992b) also examined the number and quality of ideas generated by moderated and unmoderated groups. He found no differences in quantity or quality of ideas generated by moderated or unmoderated groups. However, participants in moderated focus groups, compared to those without a moderator, reported their discussions to be more exciting, were more enthusiastic, and found their discussions more 
enjoyable. This finding seems to suggest that the role of the moderator is most important in maintaining an enjoyable aiscussion, an issue that may be important to many participants and to different uses of focus groups. There is no evidence to suggest which moderator characteristics are more important in various focus group applications. Typically no less than two and no more than 3 or 4 focus groups are conducted on any given topic. Data are summed across all groups and are reported in discussion form. Prescriptions for the analysis of group data run the gamut from very little and fairly simple to complex computer interaction analysis programs. There are strong feelings on the part of many professional focus group moderators that analyses of focus groups should remain qualitative as are the discussions they represent (Caruso 1979). These professionals caution against the inclusion of statements even hinting at quantitative measurement, for example, "most of the respondents" or "a majority of group members".

Verbatim reports of participant comments are not advised either. Rather, most guides to analyzing focus group data suggest that the analyst group similar comments and sumnarize them, using quotations to illustrate various points (e.g., Greenbaum, 1988; Templeton, 1987). The actual analysis, then, involves reviewing a tape or written transcript of a focus group and listing answers or comments to specific questions asked by the moderator. Templeton 
(1987) and others recommend using the original question guide developed and used by the moderator in the analysis process. The report can then be prepared from the list of answers and discussion on the various topics of interest.

All focus group proponents emphasize the need to interpret discussion data and draw inferences and implications to suit client needs. For example, an analyst might propose recommendations for product marketing strategies based on the group discussion of a given product (Templeton, 1987). Although this is strongly advised, there are no clear guidelines for either the analysis/ interpretation process or the training of focus group analysts. It is often assumed to be an intuitive process. Bertrand, Brown, and ward (1992), noting the lack of clear direction for analyses, provide a clear step-by-step process for compiling and analyzing focus group data. They do not, however, offer any suggestions on the interpretation and implication aspects of data analysis and report generation. The lack of direction with the more vague, but very critical, interpretive aspects of data analysis may emerge from the fact that some authors feel strongly that the group moderator should also be the data analyst and report writer so that cues available from taking part in the process are available for analysis (e.g., Axelrod, 1979). Chowdhry and Newcomb (1955) studied leaders and non leaders in estimating attitudes of group members and found that leaders were much 
better at this task because of shared interests and standards. However, many others stress only that the moderator should be part of the final report preparation and other individuals can be used to analyze the data using written transcripts or audio or videotape reproductions. (e.g., Krueger, 1994). One study has been reported examining the effect of analyst on idea quantity and quality (Nelson \& Frontczak, 1988). Four analysts were trained to code and analyze transcripts of focus group discussions. None of the analysts had moderated any of the groups but all were trained thoroughly in the coding procedures. Reliability was established before coding began. Results indicated significant differences in both the number and quality of ideas reported among the four coders. A relatively unstudied issue, this study provided evidence for strong analyst effects on data generated from focus group discussions.

The common practice should not be taken to imply that there is general consensus on how focus group data are best analyzed. There is considerable dissention on this topic. Stewart and Shamdasani (1990) suggest that the necessary interpretation and insight of focus group discussions can only come from an analysis of the content of the group process. Krippendorf (1980) describes the history of content analysis and details a variety of specific methods and techniques. Bales (1951) and Homans (1951) were among 
the first and most influential in proposing techniques for the analysis and synthesis of group interaction. Stewart and Shamdasani (1990) suggest that a number of these techniques are applicable to the analysis of focus group research. For example, procedures which classify the number of times certain people, places or things are mentioned, or the number of times the discussion elicits an emotional reaction or raising of voices, or the number of times and types of characterizations or descriptors that are used are all directly applicable to focus group discussions.

These techniques are all based on a system of unitizing or reducing data to analyzable units. Sampling units and recording these samples complete the data reduction phase (Krippendorf, 1980). Units can be defined in a number of ways with the choice of unit of analysis driven by the research objectives. Bales (1951) developed an interaction process analysis that has been used by several focus group professionals. This system provides a simple set of categories to code both verbal and nonverbal behaviors of participants as they participate in the discussion process. Krippendorf (1980) stresses that choosing content analysis categories or units may range from perceptual discrimination to sheer guesses so long as the analysts' judgements are regarded as scientific observations. Content analysis then, although appearing more scientifically worthy, must leave room for interpretation by coders or analysts. 
Regardless of what categories are used or how they are generated, data coding instructions must be detailed in advance including rules for identifying and categorizing units. Analysts or data coders must be thoroughly trained followed by assessment of reliability of coders. Once the data are coded they can be analyzed using descriptive analyses (most frequent) or multivariate methods (Jarboe, 1991). Content analysis techniques lend themselves to computer-assisted analysis. Several such computer programs exist which can greatly increase the level and detail of analysis of focus group data. This increase, however, comes at the expense of increased time and availability of computer power (Stewart \& Shamdasani, 1990). Because of this, computer assisted analysis is rarely used with focus group data.

Do focus groups generate realistic data from which conclusions and suggestions can be made? The limited research that exists suggests yes. Studies reported by Reynolds and Johnson (1979) and Ward, Bertrand, and Brown (1991) compared the results of focus groups to those of surveys and found high agreenent between the two measures. This, albeit limited, research suggests that focus groups do produce valid results.

Although there are clearly still a number of unresolved issues, focus group research is on the increase. One of the fastest growing applications is with older persons. There 
may be some factors that call into question the appropriateness of using this method, as it is currently practiced, with the elderly. Focus group techniques and procedures were developed using young adults as participants, moderators, and analysts. There has been some discussion in the literature regarding the use of children in focus groups (Greenbaum, 1988). Age effects on frequency and complexity of interaction in focus groups are discussed by stewart and Shamdasani (1990) but these all relate to the differences between children and adult group participants. There has been no research reported, to date, on any of the variables that may affect output from focus groups with older participants. The present study seeks to examine the role of age of analyst on output from focus groups with older adults.

\section{Age Differences In Focus Group Issues}

Focus group discussions are often used to generate evaluations and opinions about new products. Are there any age related differences that might differentially affect old and young groups of participants? Research on risk taking behavior may be relevant here. Botwinick (1984) reviews research conducted with older and younger persons on cautiousness and risk taking behavior. He concludes that compared to younger research participants, older persons are more cautious and less likely to take risks. Research suggests that older persons will avoid risk when possible, 
and when not, they are more cautious in the decisions they make. These studies involved giving advice to a fictional character and as such are very similar to the behavior required in many focus groups. Participants are often asked to evaluate a product and give advice on how and why it should be marketed or advertised. Botwinick's and others' research (see Botwinick, 1984) suggests that older focus group participants may offer cautious advice compared to younger participants, simply because of age differences related to task demands.

Are older consumers less willing than young to take risks in purchasing items? This answer is less clear but important since so many focus groups with older participants seek information about consumer preferences and buying habits of the older market. Schiffman (1972) conducted a study in which he found differences among elderly in their willingness to take risks in purchasing decisions. Some were much more willing to purchase a new, unknown product than others. Moreover, he found that some older adults have a higher tolerance for making an error in a risky purchase than others and this had a strong effect on purchasing decisions. This kind of research is consistent with consumer research with younger adults. Since no direct comparison of young and old consumers regarding risk taking has been made, age differences are unclear. However, the 
effects of age on risk taking behavior suggests prudence in interpreting product opinion discussions by older adults.

Do younger persons perceive themselves and others

differently than do older people? There is some evidence to suggest that they do. Toseland (1990) advises that leaders of aging groups have a more difficult time understanding the issues of their members and being empathetic, realistic, and thus effective. He asserts that this is much easier when a leader has experienced what group members have experienced, but that most group leaders are not old and cannot make themselves old to gain the needed empathy. He recommends extensive sensitization to aging issues including investigating the leader's own feelings about older persons. He cites evidence that professional helpers are more likely to underestimate capabilities of older clients.

This is consistent with other research on the perception of capabilities of the elderly. Belsky (1990), in a review of the literature, reports that research suggests that younger people tend to see older people as less competent, more physically frail, less intelligent, and at the worst time or age of life. These feelings persist in the face of reality (i.e., when confronted with healthy older people performing competent tasks) and are in contrast to the perceptions older people have of themselves and other older adults. These negative attitudes of the young toward the elderly were seen in the national survey conducted by 
Harris and Associates discussed earlier (1981). This survey revealed that younger adults perceive the elderly to have significant concerns and problems with crime, loneliness, and personal financial situation. On the part of older respondents, health concerns were rated high in importance. The concerns of the elderly rated important by young respondents were not so rated by older respondents. Belsky (1990) proposes that perceptions of elderly are changing and that with improved education realistic views of aging processes are permeating stereotypes. Ferraro (1992) provides some evidence for this, indicating that educational efforts and portrayals of elderly in literature, on television, and in movies have improved which may have an effect on socialization processes of younger cohorts.

Age differences exist in the perception of social age or the way we perceive others and ourselves to be, feel, and act. Woodruff-Pak (1988) reviews the research on cohort differences in social age and concludes that culture, ethnicity, and gender moderate the social age effects. We perceive others according to the way we have been socialized. Schaie and willis (1991) attribute differences they found in social age to early socialization effects suggesting that there are generational differences in behavioral and attitudinal flexibility and social responsibility. Bultena and Powers (1987) examined social age in people aged 60 and over and found that most older 
people see themselves as "not old" and on the average 10 years younger than their actual age. Those who admitted to being old saw themselves, consistent with the stereotypes held by the young, as frail and incompetent.

Taken together, the research on social and emotional perception of elderly show clear age related differences. Young and old have very different views about older people. It is reasonable to assume that these differences might carry over into subjective judgements of performance of the old by the young, as is currently the practice with young analysts of focus group discussions by older persons. Research by Ferris, Judge, Chachere, and Iiden (1991) provides some empirical support for this notion. These authors conducted a study in which behavior by older and younger work groups was evaluated by older and younger supervisors. They found that older supervisors rendered higher performance evaluations for older than for younger groups and younger supervisors evaluated younger groups higher than older work groups. These authors conclude that demographics can operate on a group level to affect evaluation outcome. This study provides strong evidence for the use of similar raters and group members in evaluating group behavior.

The discussion presented suggests that there is reason to examine the relative effects of young and old analysts on the outcome of focus groups. Research and practice implies 
that older group participants interact in subtly different ways compared to younger participants. Young analysts may lack the sensitivity to take the perspective of the older focus group participants. This may be the case particularly when discussion topics are those of particular concern to older persons. Older persons asked to make consumer decisions or give marketing advice may perceive those situations as risky and perform differently than would younger group participants, and in a way not obvious to younger analysts. Finally, young people have different attitudes and perceptions about older people than do the elderly themselves. Differences between young and old analysts may be more evident in the role played by analysts in drawing interpretations and recommendations based on the group discussions.

This study examined potential age differences in the analysis of focus group discussions conducted with older adults, aged 65 and over, in which participants discussed an issue of particular concern to the elderly, bathing. Data from the National Health Interview survey (National Center for Health Statistics, 1987) indicate that bathing is increasingly difficult for many older persons. Older persons report problems with and considerable concerns about the safety of bathing tasks. Several new bathtubs, showers, and other bathing systems are being introduced on the market in an attempt to address bathing concerns of the elderly. 
Focus group discussions were directed to problems experienced with bathing tasks, needs for modifications in bathing tasks, and opinions and evaluation of a new bathing system product.

Discussions are typically analyzed using either videotapes or typed transcripts of the group sessions. The use of one or the other appears to be dictated more by availability than anything else. The major difference to an analyst not present at the original group discussion is that videotapes provide contextual and nonverbal information not available in typed transcripts. It is not clear, based on the research (e.g., Bertrand, Brown, \& Ward, 1992; Stewart \& Shamdasani, 1990), what the importance is of using nonverbal behavior in analyzing focus group data. Nor is it clear if analysts would prefer using one method over another and why, and if there is a differential preference based on age of analyst. There may be subtle differences between using typed transcripts versus videotapes that affect the outcome of focus group analysis. Furthermore, age related differences in vision and processing skills may be exaggerated or diminished using videotapes or transcripts and this may differentially affect focus group analysis. This study also explored the effects on focus group output of analyzing discussion data using videotapes versus typed transcripts. 
This study was designed to test the effects of age of analyst and form of data on the analysis of focus group discussions. Understanding the relative contributions of these factors is important to designing focus group techniques which accurately assess information from older persons. There is no lack in the use of focus groups with older persons, however, the accuracy of current practice has little empirical support. This study can provide some guidelines for choosing analysts and data form when analyzing discussions with older adults.

Method

\section{Focus Group Sessions}

Three focus groups were conducted with 8 - 12 members each composed of individuals 65 and over. A trained moderator (the author) conducted the focus groups to evaluate preferences and bathing habits, problems participants have with bathing tasks, the perceived need for assistance (human or environmental) with bathing tasks, and the evaluation of a new bathing system product. Participants were recruited from advertisements in Miami, FL community newspapers and in senior living facilities and were primarily middle and upper class Jewish elders. The conduct of the focus groups was supported by a business client who developed the bathing system. A questioning route which lists discussion topics was developed by the moderator with client input. Slides and $8 "$ X 10" color 
photographs were used to introduce and demonstrate the bathing system to group participants. All groups were videotaped and audiotaped. Audiotapes were used to generate verbatim transcripts of group discussions. Discussion data were analyzed in traditional format and reported to the client. The client has agreed to allow videotapes and typed transcripts to be used in the present study. Focus group participants were paid $\$ 10.00$ for their participation by the client. Informed consent forms were administered which included a provision for the use of the videotapes for the proposed study: Only those groups whose entire membership granted permission to use the videotapes were included in the present study. Analyst Age and Form of Data

Sample. Twenty persons over the age of 60 (mean age $=$ $72.05, \underline{S D}=6.57$; range $=64$ to 83 years) and twenty persons under the age of 40 (mean age $=24.4, \underline{S D}=5.34 ;$ range $=19$ to 35 years of age) served as focus group analysts. Participants were recruited using advertisements on local college campuses and in local newspapers in Charlotte, North Carolina. All participants were screened for adequate vision and hearing capabilities through self-report. Participants were paid $\$ 10.00$ for their participation. They were told of the purpose of the study including the original purpose of the focus groups, signed informed consent forms, and were treated in accordance with the ethical procedures 
established by the American Psychological Association (1992) .

There were 4 men and 16 women in the older group of participants and 3 men and 17 women in the younger group. The older group consisted of 10 widowed, 9 married and 1 divorced individual while the younger group was comprised of 16 single, 3 married, and 1 divorced individuals. Regarding income, the majority of both groups had incomes in the midlevel range. Older participants reported the following annual incomes: $15 \%$ had less than $\$ 10,000,50 \%$ had incomes between $\$ 10,000$ and $\$ 25,000,25 \%$ reported incomes between $\$ 25,000$ and $\$ 50,000,5 \%$ between $\$ 50,000$ and $\& 75,000$, and $5 \%$ reported annual incomes over $\$ 75,000$. For young participants, the breakdown was: $15 \%$ reported less than $\$ 10,000,15 \%$ had incomes between $\$ 10,000$ and $\$ 25,000,40 \%$ reported incomes between $\$ 25,000$ and $\$ 50,000,15 \%$ between $\$ 50,000$ and $\$ 75,000$, and $15 \%$ reported annual incomes over $\$ 75,000$. Differences between age groups were not significant.

There were significant differences between younger and older participants on highest level of education completed, $E(1,38)=15,06, \underline{E}=.0004$. Older participants completed 13.55 years of school on the average $(\underline{S D}=1.76)$, while younger participants completed 15.50 years on the average $(\underline{S D}=1.40)$. This is consistent with previous findings examining age difference in education. Education is not 
considered a potential confound in this study since age differences are predicted on the basis of social experience, not skills or abilities acquired specifically through formal education.

A final demographic variable examined as a potential confound was health of participants. Health status was measured with two questions requiring participants to rate their current health status compared to that status last year, and to rate their health status relative to others of their same age. Almost all participants rated their health as the same as last year, and as the same as others in their age group. There were no age differences in either of these measures.

Materials. Videotapes and typed transcripts of the three focus group discussions were used as raw data for analysis by old and young analysts. Large print copies of transcripts were used for all participants to accommodate any potential age-related vision changes.

A set of two different measures were used to categorize the discussions in each of the focus groups (See Appendix A). The first measure was used by analysts to enumerate the number of members in each focus group who gave specific answers to questions posed by the moderator. Questions on the first form were organized according to the outline used by the moderator in the conduct of the groups. Four separate topic areas were addressed in the group discussion, 
Bathing Habits, Preferences in Bath Designs, Concerns About Bathing Safety, and Evaluation of the Comfortcare Bath system. Participants were asked to estimate how many members of each focus group answered each question in specific ways. For example, how many members reported that they "Always took a bath", how many reported that they "Sometimes took a bath", etc. There were 31 questions, in total, distributed across the four discussion topics. Each question had from 2 to 13 answers with most having 5 responses that discussion members could make and, thus, for which analysts could tally number of contributors.

The second measure used to analyze each group discussion was a modified version of Bales interaction process analysis as described by Krippendorf (1980). See Appendix A for the data collection form used. Bales' analysis rates interaction on two different levels. The first level is an information level in which participants can show any of the following behaviors: 1) gives opinion, 2) gives suggestion, 3) asks for information, 4) asks for orientation, 5) seems friendly/unfriendly, 6) agrees/disagrees, and 7) shows tension/seems relaxed. The second level of analysis categorizes socioemotional activity. Group members' behavior was rated as indicating primarily positive, negative or mixed socioemotional activity. This system was modified by having analysts rate behavior for the group as a whole. As with the 
categorization of discussion measure, socioemotional ratings were broken down by discussion topic area and the number of members contributing to the rating was estimated.

For the above two measures, estimations of number of participants who contributed to any given answer were completed using a 5 point scale reflecting that 'none', 'few', 'some', 'many', or 'all' of the focus group members contributed to the answer or made up a socioemotional rating. Category estimates were used instead of specific numbers after initial participants expressed having a lot of difficulty keeping track of exact numbers of group members. Using a scale proved to be an easier task. These measures, then, are ordinal ones with underlying continuous distributions.

A third measure was used to generate representative comments or quotes from each group regarding the four topics discussed. This is a procedure typically done in the analysis of focus group discussions. (See Appendix A for this form). Participants were asked to select and copy 1 or 2 comments from each of the four topics discussed that represented the overall opinion or "feel" of the group discussion. Quotations are often used in reports generated by focus group practitioners.

A fourth, summary measure was completed after all focus group discussions had been reviewed and categorized. (See Appendix A) Participants were asked to interpret the 
opinions expressed by members in all three focus groups in order to make marketing, distribution, pricing, and advertising recommendations to the designer of the Comfortcare system. This measure elicited interpretations in checklist and open ended question format.

A final measure dealing with reactions to and reflections on the research process, came from an exit survey. Participants rated, using 5 point Likert scales, their confidence in their ratings and recommendations, the ease with which the analysis tasks were completed, how much they could relate to the focus group discussions, and their overall feelings about participating in the study. Additional open ended questions were used to obtain more detailed information about perceived hardest and easiest tasks, and participants' own feelings about the comfortcare System.

Procedure. Participants in each age group were randomly assigned to use videotape or typed transcript to complete analyses. Each participant reviewed and analyzed all three focus groups. To control for practice effects, a Latin square was used to generate a subgroup of 3 focus group orders, and analysts in each age group were randomly assigned a different order in which to analyze the three group discussions. Practice or order effects were not considered important since the data of primary interest centered on the interpretation of all three group 
discussions. The design used in this study was a $2 \times 2$ design with two levels of age (young and old) and two forms of data or raw material (videotape and typed transcript). Both factors were between subjects factors.

Analysts were trained by the author, in small groups or individually, on rating procedures using a sample of group discussion (typed transcript or videotape depending on which medium the analysts were assigned). Analysts were asked to completely review each group discussion first before coding. Analysts watched as the author scored one complete discussion topic using the analysis forms. Analysts had a chance to ask questions and then scored the second discussion topic while the author watched. Feedback was provided and analysts conducted the remainder of the analyses alone, at a time and location of their choosing. slides and color photographs of the bathing system discussed in the focus groups were provided to analysts to use while coding group discussions.

Analysts were encouraged to conduct analyses in no more than 3 hour time blocks to avoid fatigue effects. They were asked to keep track of the amount of time spent completing analyses, but no time limits were imposed. Total time spent ranged from 1 hour to 14 hours $(M=5.96, \underline{S D}=$ 3.21). There were no significant differences in time spent between older and younger participants, nor were there any differences due to form of data. 


\section{Results}

Data were examined separately for each of the five measures in this study. The probability of a Type I error was set at .05 for all analyses. For the first two measures, categorizing discussion participation and rating informational and socioemotional interactions, data were collapsed across the three focus groups. The mean response on each question, calculated across the three focus groups served as the data for multivariate analyses of age of analyst and form of data effects. Data for the third measure, choosing representative comments from discussions, were examined for all three focus groups together. The fourth and fifth measures, product recommendations and overall reactions to the research process, were completed only once, after all focus groups were reviewed and analyzed. These data were not modified for analyses of age and form of data effects. Discussion Categorization

As mentioned previously, discussion participation was categorized separately for the 31 questions addressed in the groups. On each of these questions, there were anywhere from 2 to 13 responses that participants could make. Analysts rated the number of participants who contributed each response, using a scale ranging from 0 , no members answered in this way, to 4, all members responded in this 
manner. Each response was treated as a separate variable resulting in 143 total variables for this measure.

Each question was examined separately with all responses to that question entered into a multivariate analysis to examine age of analyst and form of data differences. This resulted in 31 sets of variables each analyzed for main effects of age, main effects of form of data, and interaction effects. These analyses revealed 9 significant effects. Given the large number of analyses performed, caution should prevail in the interpretation of significant results.

One main effect of age was found for the set of questions asking if participants would like to make modifications to their baths or showers, $\underline{E}(4,32)=2.76, \underline{P}$ $=.04$. Young analysts reported fewer discussion members ( $M$ $=2.13, \underline{\mathrm{SD}}=.65)$ who wanted to make modifications than did older analysts $(\underline{M}=1.46, \underline{S D}=.78), \underline{E}(1,35)=5.25, \underline{D}$ $=.002$.

Five multivariate analyses revealed main effects for form of data with six significant univariate tests. Five of the six univariate tests indicated that more discussion members were reported by those using transcripts than by those using videotapes. Main effects were found for type of bath or shower used, $\mathrm{E}(4,33)=4.15, \mathrm{p}=.008 ;$ frequency of taking a sit-down bath, $\underline{F}(5,31)=3.11, \underline{p}=.02$; modifications made or considered for bath, $\underline{F}(4,32)=3.83$, 
$\underline{p}=.01$; falls or slips while bathing, $\underline{E}(2,35)=3.77, \underline{p}=$ .03 ; and assistance with bathing, $\underline{E}(5,31)=2.97, \underline{p}=.03$. The means and $F$ values for the univariate analyses can be found in Table 1.

Three significant age by form of data interactions were found. For the type of bath or shower used, $E(4,33)=$ $3.53, \underline{p}=.02$, old transcript users reported more shower/bath combination users $(\underline{M}=2.53, \underline{S D}=.63)$ than young videotape users $(\underline{M}=2.33, \underline{S D}=.79)$, followed by young transcript users $(\underline{M}=2.10, \underline{S D}=.59)$, followed by old videotape users $(\underline{M}=1.85, \underline{S D}: 71) ;$ univariate $\underline{E}(1,36)=4.48, \underline{\underline{D}}=.04$. For the question asking how comfortable the comfortcare system is, the overall multivariate interaction effect was significant, $\underline{E}(5,31)=3.05, \underline{\underline{p}}=.02$. One univariate test was significant for the number of members reporting that the system was comfortable, $\underline{E}(1,35)=7.57, \underline{p}=.009$. Older transcript users reported more group members $(\underline{M}=1.39, \underline{S D}=$ 1.03) than did young transcript users $(M=.63, \underline{S D}=.62)$, and than did young videotape users $(\underline{M}=.52, \underline{S D}=.50)$, and than did old videotape users $(\underline{M}=.40, \underline{S D}=.66)$. Finally a significant interaction was found for the usefulness rating of the bath bench component of the comfortcare system, $E$ ( 5 , $32)=3.56, p=.01$. Old transcript users reported more group members who rated the bench somewhat useful $(M=1.02$, $\underline{S D}=.61)$ than did young videotape users $(\underline{M}=.83, \underline{S D}=$ $.57)$, than did young transcript users $(\underline{M}=.50, \underline{S D}=.40)$, 
and than did old videotape users $(\underline{M}=.38, \underline{S D}=.40) ; \underline{F}(1$, $36)=9.43, \underline{p}=.004$.

Informational and Socioemotional Interaction Ratings

The data assessing the seven types of behaviors that make up the informational level of interaction (Gives Opinion, Gives Suggestions, Asks for Information, Asks for orientation, seems Friendly, Agrees, and Seems Relaxed) were subjected to multivariate analyses of variance separately for each of the four topic areas discussed in the focus groups (Bathing Habits, Bathing Preferences, Concerns About Bathing Tasks, and Product Reaction).

There were seven significant results for this measure. For three of the four discussion topics, analysts who used transcripts reported more group members who "Asked for Information" than did those who used videotapes. For the discussion of bathing habits, there was an advantage of using transcripts for "Asks for Orientation" while the topic of concerns about bathing tasks yielded higher transcript scores for "Seems Friendly". See Table 2 for the means and F values for informational level results.

Finally for the product reaction discussion, a significant main effect of age was found for two of the seven informational level behaviors, suggesting that young analysts reported more members contributing to "Asks for Information" and "Agrees" than did older analysts. (These results can be seen in Table 3 ) 
There were no significant effects for the analyses of the second level of interaction process, socioemotional activity, indicating that analysts reported the same number of members exhibiting positive, negative, or mixed emotions, regardless of age or form of data used.

\section{Representative Comments}

No analyses were possible with this third measure since many participants did not complete this form correctly, and several did not complete it at all. Participants were told, and seemed to understand during training, to use this form to report quotes from the group that reflected the general discussion of the four major topics. Only $38 \%$ of participants overall completed the forms in this way. Another $38 \%$ provided summaries of the discussion and another $25 \%$ did not complete this form at all. Interesting here is the breakdown of this response pattern according to age and form of data. Only $10 \%$ of the 20 older analysts reported quotes while 50\% summarized discussions, and $40 \%$ did not complete this task. For the young analysts, $65 \%$ chose quotes, $25 \%$ summarized the discussions, and $10 \%$ did not complete this task. Several analysts remarked that focus group members did not agree on much. Task performance of older adults, then, may reflect an attempt to provide more accurate information regarding the discussions rather than a misunderstanding of task requirements. Given this argument, younger analysts may have been more likely to ignore 
disagreement on the focus groups and choose quotes that represented at least some of the discussion members" opinions.

With regard to form of data differences on this responses, it might make sense to predict more summaries from those who used videotapes and more quotes from those who used typed transcripts since quotes could be directly copied from transcripts but would take more time and be more difficult to glean from videotapes. This was not supported with $50 \%$ of the videotape sample reporting summaries, $40 \%$ reporting quotes and $10 \%$ not completing the form. For the transcript group, 25\% reported quotes, 35\% reported summaries and another $40 \%$ didn't complete the form. Product Recommendations

Data from this fourth measure, product marketing and advertising recommendations, were examined using chi square analyses for nominal variables and multivariate analyses for score data.

There were no significant differences due to form of data on any of the variables examined. There were significant age group differences for two variables dealing with marketing and advertising the Comfortcare Bath system. older analysts (55\%) were more likely than younger analysts (20\%) to recommend that the system be put on the market as it is, or not be put on the market at all (the two extreme categories) whereas younger analysts ( $80 \%$ ) were more likely 
than older analysts (35\%) to recommend major modifications in the system before marketing it, $\chi^{2}(4, \underline{N}=40)=10.64, \underline{D}$ $=.03$. OnIy 2 participants, both in the older group, reported not being able to make a recommendation. Older analysts were more likely to restrict their choices on how the system should be introduced to the market (i.e., how and where it should be advertised or shown) while younger analysts spread their marketing strategy recommendations across several categories, with a majority favoring the placement of a model system in retirement and housing developments, $\chi^{2}(5, \underline{N}=36)=13.35, \underline{p}=.02$. The categories and frequency distributions for this variable can be seen in Table 4 . None of the other Chi Square analyses or MANOVAS revealed significant differences including: recommendations for target users or buyers, predicted success of product, price of product, or modifications to the product.

Reactions to Research process

For this fifth measure, chi square analyses, MANOVAS and ANOVAS were conducted on the data from the Exit Survey in order to examine age and form of data effects on confidence ratings, ease of rating discussion participation, and reactions to participating in the research study.

A multivariate analysis of variance was performed on the data from the 8 confidence ratings in order to examine age and form of data effects on the confidence 
analysts felt in categorizing and interpreting discussions and emotions, and making product recommendations. The overall MANOVA revealed no main or interaction effects. However, two univariate tests were significant. Analysts who used transcripts were less confident in choosing representative comments $(\underline{M}=2.25, \underline{S D}=1.01)$ than were those coding from videotapes $(\underline{M}=3.00, \underline{S D}=1.26), \underline{F}(1,36)$ $4.26, \underline{D}=.05$. A significant interaction between form of data and age group was found for confidence in rating the emotional nature of the discussion groups, $E(1,36)=6.48$, $\underline{p}=.015$. Older transcript users were the least confident $(\underline{M}=1.90, \underline{S D}=.99)$, followed by young analysts using video formats $(\underline{M}=2.20, \underline{S D}=.79)$. Older analysts using videotapes $(\underline{M}=2.80, \underline{S D}=1.22)$ and young transcript users $(\underline{M}=3.10, \underline{S D}=1.37)$ were the most confident.

A MANOVA examining three ease of rating measures indicated no significant overall main or interaction effects for age group or form of data. Again, however, a number of univariate comparisons were significant. The results for the general question, "How easy was it for you to rate the opinions expressed by the focus group members?", showed that older analysts found this a more difficult task than did younger analysts, $\mathrm{E}(1,36)=4.48, \mathrm{p}=.04$. On a 5 point scale with 1 indicating "Very Easy" and 5 indicating "Very Difficult", older raters had a mean rating of 3.25 (SD 
$=1.12)$, whereas younger raters had a mean rating of 2.55 $(\underline{S D}=.94)$.

A multivariate analysis was performed using three measures dealing with analysts' reactions to the study: a rating on a 5 point scale of how they liked participating in the study, a rating on a 5 point scale of how much they felt they could relate to the discussions held in the three focus groups, and how much time they spent completing the analyses. There was a significant overall main effect of form of data, $\underline{F}(3,34)=8.08, \underline{Q}<.001$. Univariate tests revealed that those who analyzed using transcripts reported that they related to the discussions significantly more ( $M$ $=4.15, \underline{S D}=1.04$ ) than did those who used videotape formats $(\underline{M}=2.55, \underline{S D} 1.27), \underline{E}(1,36)=22.93, \underline{p}<.001$. There was no overall interaction effect or main effect of age. There was a significant univariate interaction, $F(1,36)=5.73, p$ $=.02$, and a significant univariate main effect of age, $E$ $(1,36)=4.38, \underline{p}=.04$, for the measure of how much they related to the discussions they analyzed. Older analysts related more $(\underline{M}=3.70, \underline{S D}=1.22)$ than younger analysts ( $\underline{M}$ $=3.00, \underline{S D}=1.52) ;$ and younger users of transcripts $(M=$ 4.20, $\underline{S D}=.92)$, and older users of transcripts $(\underline{M}=4.10$, $\underline{S D}=1.20)$ and videotapes $(\underline{M}=3.30, \underline{S D}=1.16)$ related more to the discussions than did younger users of videotapes $(M=$ $1.80, \underline{\mathrm{SD}}=.92)$. 
Chi square analyses were used to examine age group and form of data differences on analysts' own reactions to the bath system, the rating tasks perceived to be the hardest and the easiest, whether confidence in rating and ease of rating was the same or different for all three focus groups, and if they felt they could keep their own opinions about bathing and the comfortcare bath system separate from their interpretations of the opinions of focus group members. only this last analysis was significant and only for age group, $\chi^{2}(1, \underline{N}=40)=11.90, \underline{p}=.0006$. older analysts were almost evenly divided between saying yes they could keep their opinions separate, and no they could not ( $55 \%$ versus $45 \%$ ) whereas all but 1 of the younger analysts said they could keep their opinions separate.

\section{Discussion}

Before offering conclusions and implications of these findings it is prudent to note that the results of this study must be viewed with caution given the small sample size. In addition, the lack of random sampling limits the generalizability of results. However, given the limited number of studies on focus groups in general, the complete absence of research on the use of focus groups with older participants, and the call by practitioners for empirical evaluation (Morgan, 1993), this study offers some needed insight that can benefit both research and practice. 
Findings from this study suggest that age and form of data may not have an effect on what analysts see or categorize in a focus group discussion but may produce subtle differences in some aspects of how discussions are interpreted. The first measure of discussion categorization, a simple estimate of numbers of responses made by focus group members, revealed no substantial differences that can be attributed to age of analysts or form of data used. It appears that both young and old raters are able to quantify discussions, although many respondents reported this as the hardest task to complete. Still others expressed their strong dislike of having to "count people". Many respondents, more in the older group than the younger group, expressed a hard time staying on task and needed many breaks. The final result, however, was the same for all analysts regardless of age or form of data. Socioemotional ratings were predicted to differ by age based on previous research suggesting that older and younger individuals interact differently and perceive one another differently. In addition, it was thought that videotapes might provide important nonverbal behavior cues and thus produce differences in ratings of emotions. However, there were no differences due to age or form of data on activity of socioemotional behavior. Both old and young, transcript and videotape users, evaluated the overall emotional nature of the focus groups in much the same way. There were some 
differences in the informational level of socioemotional behavior with those who used transcripts reporting significantly more focus group members who expressed certain behaviors than did those who analyzed from videotapes. This suggests that, contrary to expectations, nonverbal cues available in videotapes do not make it easier to rate the emotional nature of individuals in groups. Perhaps videotapes of group discussions impair analysts' ability to observe and record specific types of interaction. There is a lot to keep track of in a video and background light and noises can provided significant distractions. Many analysts commented on distractions in the videotapes. It may have been easier to record information from typed transcripts. There were, however, no differences between transcript and videotape users on ease of completing the group analysis. It is interesting to note, however, that although transcripts may produce less interference, using them to rate the opinions of others is not done so with much confidence by older analysts.

Transcripts did not seem to provide an advantage over videotapes when choosing quotes. Analysts who chose quotes or summarized discussions were as likely to do that with transcripts or videotapes. However, more older persons chose not to report quotes and not to complete this task at a11. Those who did most often summarized the discussion. As mentioned earlier, perhaps this is due to the fact that 
older analysts recognized the diversity of the focus group discussions while young analysts chose to ignore this diversity and comply with the demands of the task, to select representative quotes.

What about interpretation of focus group discussions in order to judge opinions about the bath product and make marketing decisions? There was no effect of form of data here so interpreting opinions of group members does not seem to be affected by interference or nonverbal cues from videotaped discussions. There were differences due to age group but contrary to what previous literature has suggested. Rather than being more cautious and less likely to provide advice on marketing the bath system, older analysts were more likely to recommend marketing the bath as is or not marketing it at all. Only two older analysts chose to withhold giving marketing advice. Only one young analyst recommended not marketing the bath with most suggesting major modifications before marketing. Few older analysts chose this option. The least risky option might be to choose to not market the product, in which case older analysts were much more likely to choose this low risk category than young, but they were also more likely to choose the most risky category. This finding supports earlier marketing research by Schiffman (1972) indicating that some older consumers will make risky purchasing decisions while others will not. It would be wise for market 
research to examine this difference more closely in future research to see if any underlying predictors, such as socioeconomic status, health status, or consumer history can be identified. It is interesting to note that older analysts did find rating opinions to be more difficult than did younger analysts. However, neither group reported having much difficulty with this task.

What about other types of marketing decisions? While $45 \%$ of the young analysts thought the bath should be targeted to older users, most older analysts (65\%) thought that both older people and institutionalized persons, equally, should be targeted as users. This may reflect a lessening of stereotypes on the part of both young and old regarding the perceived reluctance on the part of older persons to try new products. Both young and old analysts thought that retirement facilities and nursing homes would be likely buyers for the system. A few respondents in both age groups thought individuals might purchase the system discussed, but older analysts qualified this by saying that rich individuals would be likely consumers.

older analysts thought marketing strategies should be diverse, younger analysts thought models in retirement homes and institutions was the best strategy. This may reflect a better understanding of the diversity of consumers on the part of older analysts. 
Predictions that older analysts would be more empathetic or show more understanding of other older persons were partially supported. Older analysts reported that they related more to the discussion than did young analysts. An interesting effect of form of data and an interaction between age and form of data suggests that transcripts provided information to which both young and older analysts could relate. Furthermore, the advantage of transcripts was stronger for young than old analysts. Perhaps, as stated earlier, videotapes interfere with being able to relate to the discussion for young analysts. This finding is consistent with the review by Woodruff-Pak (1988) suggesting that culture and ethnicity moderate social age effects. Focus group members were from South Florida and primarily middle and upper class Jewish elders. Most of the young analysts in this study were southern students attending a private presbyterian college. Cultural differences between analysts and group members would stand out in the videotapes and may be masked in the transcripts and thus could have produced the very low ratings on this measure. Are older analysts affected by cultural differences? There is some evidence that they are. older analysts using videotapes had the second lowest rating scores on how much they related to the discussion. Perhaps the shared experience of aging offset some of the personal distance produced by ethnic and racial differences. 
Another possible explanation for these findings requires looking at not why videotape use interferes with analysis for young users and less so for old analysts, but rather, why transcript use enhances the performance of young analysts but does not do so for old analysts. An explanation can be found in the literature on school effects (e.g., Cole, 1981; Scribner \& Cole, 1981; Rogoff \& Lave, 1984). School environments are unique compared to everyday life settings. School settings and settings which are "school-like" produce very stereotypical ways of responding. The use of transcripts to complete focus group analysis can be seen as a more school-like task. Perhaps, young analysts, with recent school experience, responded to this school-like task in typical school-like ways. The older analysts' exposure to school is much more distant and they would not be as likely to react to a school-like task in the same manner. Thus, differences due to more recent experience in school could have contributed to the young-old differences seen for those using transcripts.

Taken together the results of this study provide some support for using older persons to complete the analysis of focus groups held with older persons. Overall, the number of significant results were few relative to the number of analyses conducted. Moreover, there was no difference between old and young in objective measures of group discussion categorization. While this indicates that using 
young analysts for focus groups held with older persons is not detrimental to the outcome, it also suggests that there is no reason NOT to use older analysts. Further, it may be better, since older individuals appear to interpret the opinions of other older individuals slightly differently than do younger analysts. Given the importance of using moderators that share empathy with and understanding of focus group members, and their important role in final report development, older persons should be recruited to serve as moderators and as analysts. Several older participants in the present study expressed an interest in part time employment and thought they would enjoy and be quite competent at the task of focus group analysis.

With regard to form of data for completing focus group analysis, the results suggest that transcripts may be a better method for both young and old analysts than videotapes. This is good news for those who use focus groups since transcripts are much easier and more economical to produce. Nonverbal cues from videotapes of group discussions do not appear to be helpful but rather, may interfere with categorization, interpretation of emotions, and empathizing with the discussion. It is important to remember that when providing older analysts with transcripts, large print and other alternate formats are critical to help offset age related changes in vision. older participants in this study noted their appreciation of 
large print (some young analysts were not as enthused) and enjoyed the fact that they could complete the task at a time and location convenient to them. Given the problems many older workers have with transportation, tasks that can be completed at home would be very welcome. Given the growing numbers of older persons, it is imperative that we draw on their expertise and experience in making decisions that affect this significant proportion of our population. 
References

American Psychological Association. (1992). Ethical principles of psychologists and code of conduct. American Psychologist, 47, 1597-1611.

Axelrod, M. D. (1979). Ten essentials for good qualitative research. In J. B. Higgenbotham, \& K. K. Cox (Eds.). Focus group interviews: A reader (pp.50-51). Chicago: American Marketing Association.

Bales, R. F. (1950). Interaction process analysis: A method for the study of small groups. Cambridge, MA: Addison-Wesley Press.

Bellenger, D. N., Bernhardt, K. L., \& Goldstucker, J. L. (Eds.). (1976). Qualitative research in marketing. Chicago: American Marketing Association.

Belsky, J. K. (1990). The psychology of aging: Theory. research, and interventions. (2nd ed.). Pacific Grove, CA: Brooks/Cole.

Bertrand, J. T., Brown, J. E., \& Ward, V. M. (1992). Techniques for analyzing focus group data. Evaluation Review, 16, 198-209.

Bivens, J. (August, 1988). Retailers slow to target older customers: Failure to understand $50+$ customers hampers marketing efforts. Chain Store Age Executive, 135-136. Botwinick, J. (1984). Aging and Behavior. New York: Springer. 
Bultena, G. L. \& Powers, E. A. (1987). Denial of aging: Age identification and reference group orientations. Journal of Gerontology, 33, 748-754.

Caruso, T. E. (Ed.). (1979). Moderators focus on groups: Session yields 7 hypotheses covering technology trend, professionalism, training, techniques, reports, etc. In J. B. Higgenbotham, \& K. K. Cox (Eds.). Focus group interviews: A reader (pp. 55-59). Chicago: American Marketing Association.

Chowdhry, K. \& Newcomb, T. M. (1955). The relative abilities of leaders and non-leaders to estimate opinions of their own groups. In A. P. Hare, E. F. Borgatta, \& R. F. Bales (Eds.). Small groups: studies in social interaction (pp. 235-245). New York, NY: Knopf.

Coe, B. J. \& MacLachlan, J. (1980). How major tv advertisers evaluate commercials. Journal of Advertising Research, 51-54.

Cole, M. (1971). The cultural context of learning and thinking: An exploration in experimental anthropology. New York, NY: Basic Books.

Fern, E. (1982a). Why do focus groups work: A review and integration of small group process theories. In $A$. Mitchell (ed.), Advances in Consumer Research. Ann Arbor: University of Michigan.

Fern, E. $(1982 \mathrm{~b})$. The use of focus groups for idea generation: The effects of group size, acquaintanceship, 
and moderator on response quantity and quality. Journal of Marketing Research, 19, 1-13.

Ferraro, K. F. (1992). Cohort change in images of older adults, 1974-1981. Gerontologist, 32, 296-304.

Ferris, G. R., Judge, T. A., Chachere, J. G., \& Liden, R. C. (1991). The age context of performance-evaluation decisions. Psychology and Aging, 6, 616-622.

Gilly, M. \& Zeithmal, V. M. (1985). The elderly consumer and adoption of technologies. Journal of Consumer Research, 476-482.

Goldman, A. E. (1962). The group depth interview. Journal of Marketing, 26, 61-68.

Greco, A. C. (1988). The elderly as communicators: Perceptions of advertising practitioners. Journal of Advertising Research, 82-86.

Greenbaum, T. L. (1988). The practical handbook and guide to focus group research. Lexington, MA: D.C. Heath and Company.

Harris, L. \& Associates. (1981) Aging in the eighties: America in transition. Washington D.C.: National Council on the Aging.

Hess, J. M. (1968). Group interviewing. In R. L. King (Ed.), 1968 ACR Fall Conference proceedings (pp. 193-196). Chicago: American Marketing Association.

Homans, G. C. (1951). The human group. New York, NY: Harcourt, Brace. 
Jarboe, S. (1991). Two multivariate methods for analyzing small group interaction: A database comparison. Smal1 Group Research, 22, 515-547.

Kiley, D. W. (1988). Sixty - and never been younger. Adweek's Marketing Week, 66-69.

Krippendorf, K. (1980). Content analysis. Beverly Hills, $C A$ : Sage Publications.

Krueger, R. A. (1994). Focus groups: A practical quide for applied research (2nd ed.). Newbury Park, CA: Sage Publications.

Linden, Fabian. (1986, February). "The $\$ 800$ billion market." American Demographics.

Mertz, B. \& Stephens, N. (1986). Marketing to older American consumers. International Journal of Aging and Human Development, 23, 47-58.

Morgan, D.L. (Ed.). (1993). Successful focus groups. Newbury Park, CA: Sage Publications.

Morgan, D. L. (1988). Focus groups as qualitative research. Newbury Park, CA: Sage Publications.

Nelson, J. E. \& Frontczak, N. T. (1988). How acquaintanceship and analyst can influence group results. Journal of Advertising, 17, 41-48.

National Center for Health Statistics. (1987). D. Dawson, G. Hendershot, \& J. Fulton, Aging in the eighties: Functional limitations of individuals age 65 years and over. AdvanceData from Vital and Health Statistics, No. 133. 
(DHHS Pub. No. [PHS] 87-1250). Hyattsville, MD: Public Health Service.

Resener, M. R. \& Prout, L. E. (1986, January 6). Targeting the old folks: Florida leads the way in marketing to the elderly. Newsweek, 39-41.

Reynolds, F. D. \& Johnson, D. K. (1979). Validity of focus group findings. In J. B. Higgenbotham, \& K. K. Cox (Eds.). Focus group interviews: A reader (pp. 110-113). Chicago: American Marketing Association.

Rogoff, B. \& Lave, J. (Eds.). (1984). Everyday cognition: Its development in social context. Cambridge, MA: Harvard University Press.

Rosse11, C. (June, 1987). Segmenting seniors: More and more firms are using a sensitive touch to reach the growing older American market. Target Marketing, 13-14.

Schaie, K.W. \& Willis, S.L. (1991). Adult personality and psychomotor performance: Cross-sectional and longitudinal analyses. Journal of Gerontology: Psychological sciences, 46, 275-284.

Schiffman, L. G. (1972). Perceived risk in new product trial by elderly consumers. Journal of Marketing Research, $9,106-108$.

Schneidman, D. S. (1988, February). older consumers adopt baby-boomer buying behavior. Marketing News, $72-74$. Scribner, S. \& Cole, M. (1981). The psychology of 1iteracy. Cambridge, MA: Harvard University Press. 
Stephens, N. L. \& Warrens, R. A. (1983). Advertising frequency requirements for older adults. Journal of Advertising Research, 531-535.

Stewart D. W. \& Shamdasani, P. N. (1990). Focus groups: Theory and Practice. Newbury Park: Sage Publication. Templeton, J. F. (1987). Focus groups: A guide for marketing and advertising professionals. Chicago: Probus Publishing Company.

Torp, J. (1991, March). Sizing up the senior market. Paper presented at the American Society on Aging Conference, New Orleans, LA.

Toseland, R. W. (1990), Group work with older adults. New York: New York University Press.

U.S. Department of Health and Human Services. (1987). A Profile of Older Americans: 1986. Washington, DC: Program Resources Department, American Association of Retired Persons (AARP) and the Administration on Aging $(A O A)$.

U.S. Public Health Service, National center for Health statistics. (1986). Monthly vital statistics report, $35(6)$. Supplement 2, Advance report of final mortality statistics, 1984. Washington, DC: U.S. Government Printing office. U.S. Senate Special Committee on Aging. (1987). Aging America: Trends and projections (1987-1988 ed.). Washington DC: U.S. Dept. of Health and Human Services. 
Ward, V. M., Bertrand, J. T., \& Brown, L. F. (1991). The comparability of focus group and survey results: Three case studies. Evaluation Review, 15, 266-283.

Woodruff-Pak, D. S. (1988). Psychology and aging.

Englewood Cliffs: Prentice-Hall.

Yoel1, W. A. (1979). How useful is focus group interviewing? Not very ... post-interviews reveal. In $\mathrm{J}$. B. Higgenbotham, \& K. K. Cox (Eds.). Focus group interviews: A reader (pp. 119-123). Chicago: American Marketing Association.

Zopf, P. E., Jr. (1986). America's older population. Houston, TX: Cap and Gown Press. 
Table 1

Mean Transcript and Videotape Users' Estimate of Number of Focus Group Members Contributing to Discussion Questions

\section{Form of Data}

Answers to

Video Transcript

Discussion

Questions

M

SD

M

SD

$\underline{E}$

Use Shower

stalls

$$
.92
$$

.56

1.33

.54

5.25

Made Bath

Modifications

2.04

.48

1.51

.74

6.56

Do Not Want

Bath

Modifications

$.40 \quad .53$

1.07

.93

7.17

(table continues) 
Form of Data

Answers to

Discussion

Video Transcript

Questions

$M \quad \underline{S D}$

$\underline{\mathrm{SD}}$

E

Have Not

Slipped or

Fallen in Bath

1.52

1.02

2.38

1.11

$7 \cdot 34$

Never Have

Assistance

Bathing

1.02

1.05

2.13

1.22

9.47

Never Take a

Sit-down Bath

.92

.75

1.67

.80

9.90

All p values $<.05$ 
Table 2

Mean Transcript and Video Users' Estimates of Number of

Eocus Group Members contributing specific Interaction

Informational Behaviors

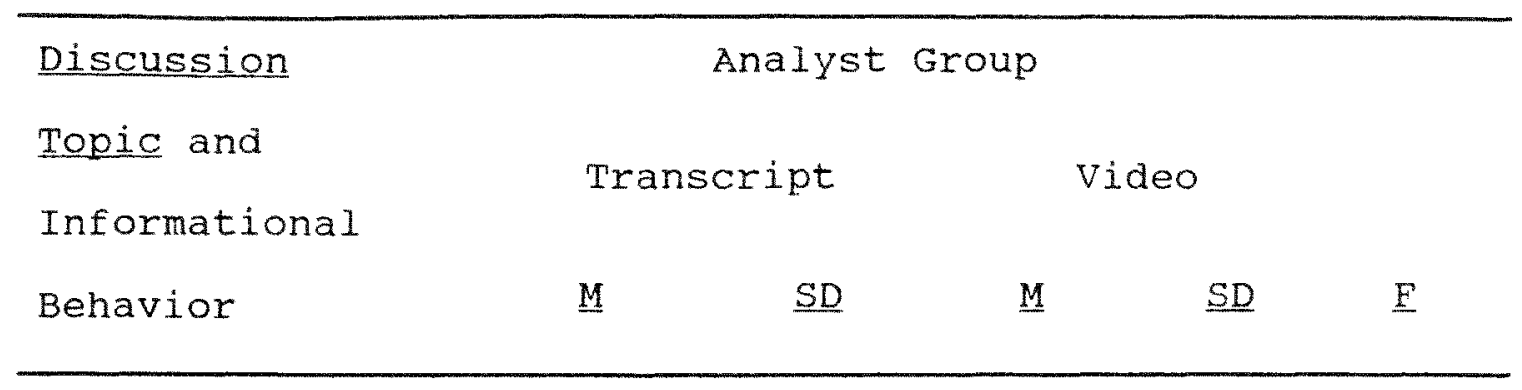

Bathing Habits

Asks for

$\begin{array}{llllll}\text { Information } & 1.40 & .81 & .77 & .60 & 8.54 *\end{array}$

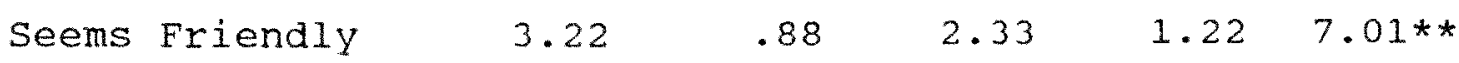

Concerns about.

Bathing Tasks

Asks for

$\begin{array}{llllll}\text { Information } & .95 & .66 & .44 & .47 & 8.15 * *\end{array}$

(table continues) 


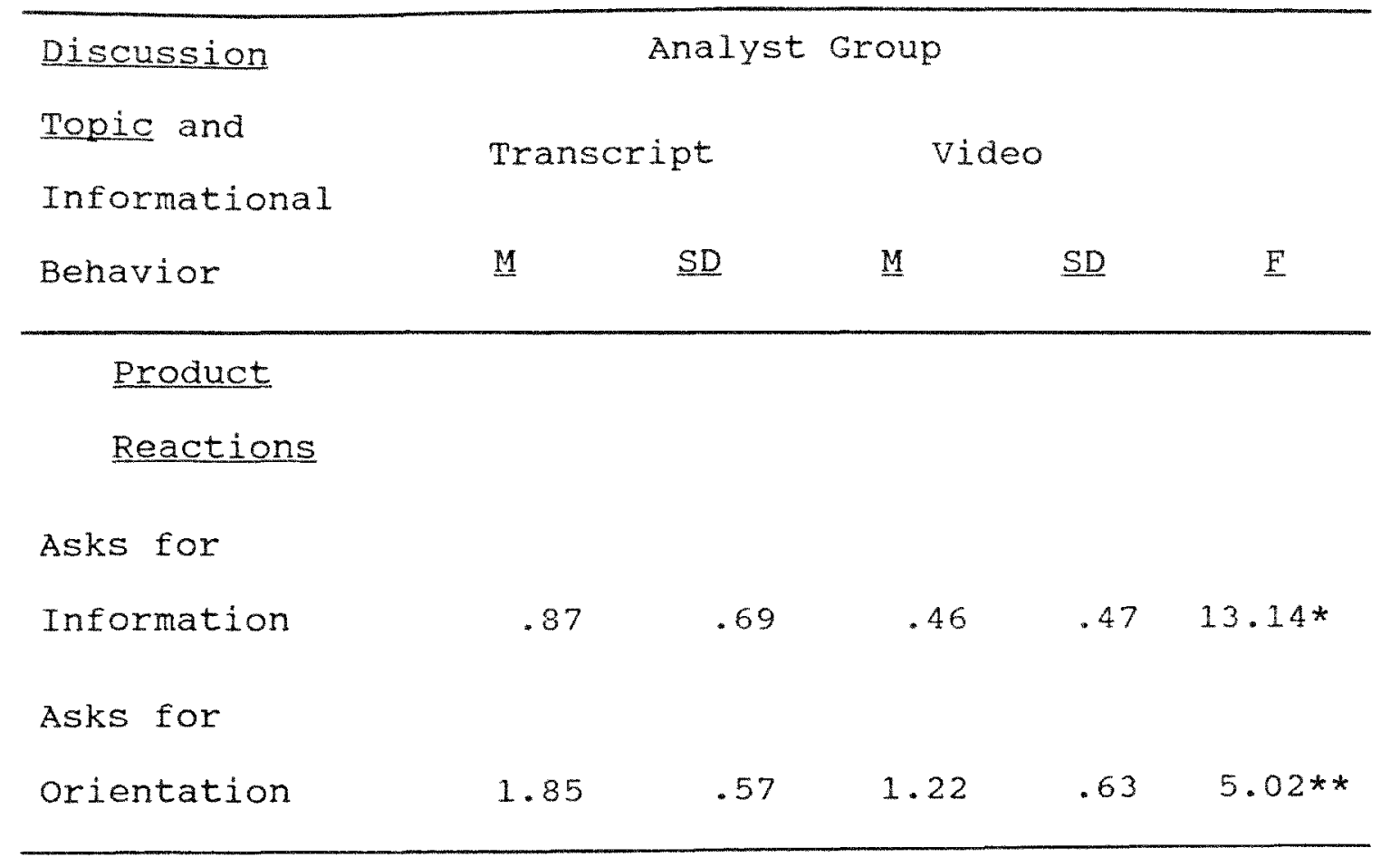

$* \mathrm{p}<.01, * * \mathrm{p}<.05$ 
Table 3

Mean $01 d$ and Young Analysts' Estimates of Number of Focus Groups Members contributing Specific Informational Behaviors to Product Reaction Discussions

\section{Analyst Group}

Informational

Behavior
Old
Young

$M$

SD

M

SD

E

Asks for

Information

1.29

.65

1.78

$.618 .13 *$

Agrees with

\begin{tabular}{llllll} 
Group & .53 & .68 & 1.01 & .69 & $4.89 * *$ \\
\hline
\end{tabular}

$\star \mathrm{P}<.01, * * \mathrm{p}<.05$ 
Table 4

Marketing strategies Recommended by old and young Analysts

Frequency

Marketing strategy

old

Young

Place a model in retirement

or housing developments

2

7

Demonstrate at trade shows

8

1

Ads in magazines and TV

5

3

contact bath suppliers

0

1

contact home builders

0

3

Ads in trade publications

3

2

Note. Distributions were significantly different by age, $\chi^{2}$ $(5, \underline{\underline{N}}=35)=12.90, \underline{\mathrm{P}}, .05$ 


\section{APPENDIX}

\section{DATA COLLECTION FORMS: Discussion Ratings}

Below is a list of questions discussed by focus group members. For each question listed below, please estimate HOW MANY group members expressed that particular answer.

I. Bathing Habits

1) How often do you take a sit down bath?

Always

Frequently

Sometimes

Rarely

Never group members group members group members group members group members

2) How often do you take a shower?

Always

Frequently

Sometimes

Rarely

Never group members group members group members group members group members

3) How often do you bathe at the sink?

Always

Frequently

Sometimes

Rarely

Never group members group members group members group members group members

4) Do you receive assistance with bathing tasks?

Always

Frequently

sometimes

Rarely

Never group members group members group members group members group members

5) Do you have any difficulty with bathing tasks?

A Lot of Difficulty Some Difficulty No Difficulty group members group members group members 


\section{APPENDIX}

DATA COLLECTION FORMS: Discussion Ratings (continued)

6) If you experience any difficulty, which of the following types of difficulties have you experienced?

stepping in and out of the bathtub sitting down in the bathtub Getting up from a seated position in the bathtub Turning faucets off and on Adjusting water temperature standing while showering Keeping balance while showering Reaching for washcloth, soap, etc. Reaching for faucets or handles Reaching grab bars

Reaching to wash hair or body Drying off after bathing other members members members members members members members members members members members members members

II. Bathing Preferences

1) What type of bath/shower do you currently have?

Shower/Bath combination Shower stall only

Bathtub only

Both a shower stall AND a combination unit group members group members group members group members

2) How satisfied are you with your present bath/shower?

Very Satisfied

Satisfied

Neutral

Dissatisfied

very Dissatisfied

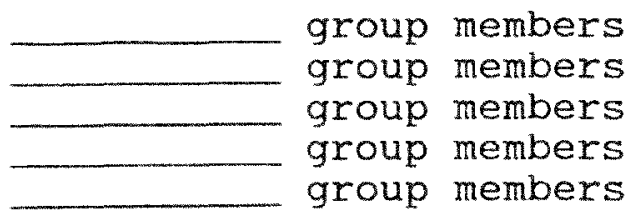

3) What type of bath/shower design do you prefer?

Shower/Bath combination Shower stall only

Bathtub only

Both a shower stall AND a combination unit No preference group members group members group members group members group members 


\section{APPENDIX}

DATA COLLECTION FORMS: Discussion Ratings (continued)

III. Concerns About Bathing Tasks

1) Are you concerned about falls, slips or injuries while bathing?

Very Concerned

Concerned

Neutral

Unconcerned

Not at All Concerned

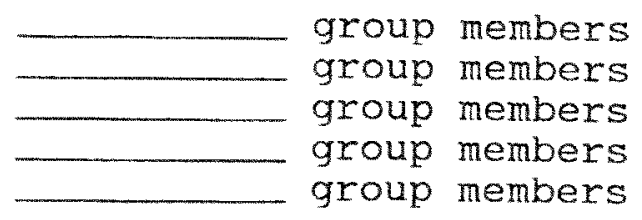

2) How safe is your bath/shower?

Very Safe

Safe

Neutral

Unsafe

Very Unsafe

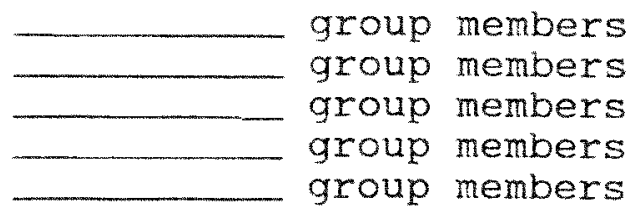

3) Have you ever slipped or fallen in your bath/shower?

Yes

No

group members group members

4) Do you know anyone who has slipped or fallen in the bath or shower?

yes

No group members group members

5) Have you made additions to or modifications in your bath/shower to address your concerns?

Yes

group members

No group members

6) Would you like to make additions to or modifications in your bath/shower to address your concerns?

Yes

group members

No group members 
APPENDIX

DATA COLLECTION FORMS: Discussion Ratings (continued)

7) If yes to question 5 or 6 , what type of additions or changes?

A movable shower/bath seat or bench

An attached seat area

in the bath/shower

one or more grab bar rails

A non slip mat

A non slip surface

on bathtub floor

other

IV. Comfortcare Product Reaction

1) How useful is the add-on seat?

Very Useful

Somewhat Useful

Neutral

Somewhat Not Useful

Not at All Useful

members

members

members

members

nembers

members

2) How useful is the add-on full-length bench?

Very Useful

Somewhat Useful

Neutral

Somewhat Not Useful

Not at All Useful group members group members group members group nembers group members

3) How useful is the add-on easy access bath tube?

Very Useful

Somewhat Useful

Neutral

Somewhat Not Useful

Not at All Useful group members group members group members group members group members

4) How important is the recessed water inlet?

Very Important

Important

Neutral

Not Important

very unimportant group members group members group members group members group members 


\section{APPENDIX}

DATA COLLECTION FORMS: Discussion Ratings (continued)

5) How important is the built in shelf support?

Very Important

Important

Neutral

Not Important

Very Unimportant

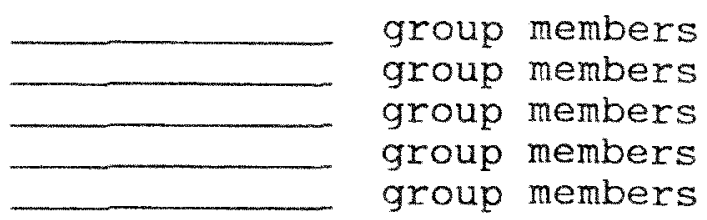

6) How attractive is the comfortcare system?

Very Attractive

Attractive

Neutral

Not Attractive

Very Unattractive

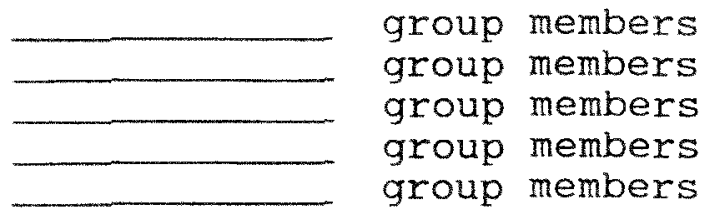

7) How comfortable does the comfortcare system appear to be?

Very Comfortable

Comfortable

Neutral

Not Comfortable

Very Uncomfortable

group members group members group members group members group members

8) How important is ease of cleaning in a bath or shower unit?

Very Important

Important

Neutral

Not Important

very Unimportant

group members group members group members group members group members

9) Do you think the comfortcare system is easy to clean?

Yes

group members

No group members

Cannot determine group members

10) How important is safety in a bath or shower unit?

Very Important. Important Neutral

Not Important very Unimportant

group members group members group members group members group members 


\section{APPENDIX}

DATA COLLECTION FORMS: Discussion Ratings (continued)

11) Do you think the Comfortcare System provides for safety?

Yes

No

Cannot determine

group members group members group members

12) How important is convenience in a bath or shower unit?

Very Important Important

Neutral

Not Important

Very unimportant

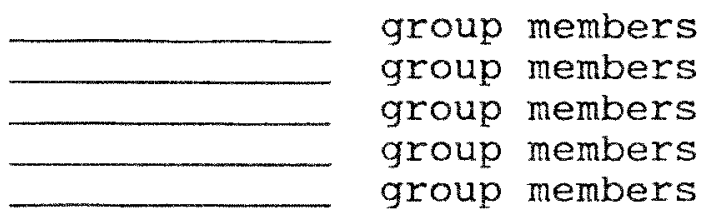

13) Do you think the comfortcare system is convenient?

Yes

No

Cannot determine

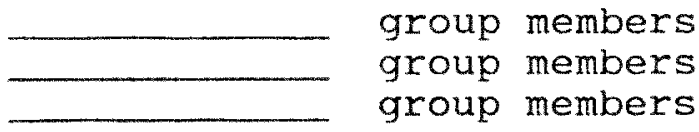

14) How useful is having the option to change the Comfortcare system from a standard bath to one with more assistive features?

Very Useful

Useful

Neutral

Not Useful

Not at all useful

group members group members group members group members group members

15) In general, how much do you like the comfortcare system?

Like it Very Much

Like it

group members

Neutral

Dislike it

Dislike it very Much

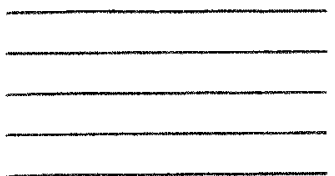
group members 
DATA COLLECTION FORMS: Informational Level Ratings

For each of the topics discussed in the focus group, rate the participation of the group members according to type of interaction. Estimate how many group members contributed each type of interaction to the discussion topics isted below. Group members could express any of the types of interactions 1 isted below so they can be in more than one category.

\section{Bathing Habits}

Gives Opinion

Gives Suggestions

Asks for Information

Asks for orientation

Seems Friendly

Agrees

Seems Relaxed

\section{Bathing Preferences}

Gives opinion

Gives Suggestions

Asks for Information

Asks for orientation

Seems Friendly

Agrees

Seems Relaxed

Concerns About Bathing Tasks

Gives Opinion

Gives Suggestions

Asks for Information

Asks for orientation

Seems Friendly

Agrees

Seems Relaxed

\section{Product Reactions}

Gives Opinion

Gives Suggestions

Asks for Information

Asks for orientation

Seems Friendly

Agrees

seems Relaxed group members group members group members group members group members group members group nembers

group members group members group members group members group members group members group members

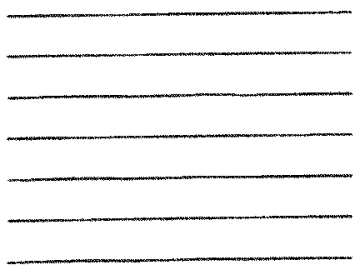

group members group members group members group members group members group nembers group members

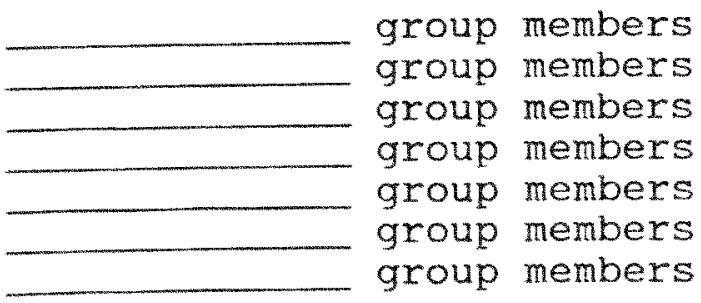




\section{APPENDIX}

DATA COLLECTION FORMS : SOcioemotional Ratings

Over all discussion topics (e.g., the entire session), rate the emotional nature of the focus group. Think of this as a general "feel" you got from listening to or reading the discussions. Estimate how many group members expressed these emotions.

Primarily Positive in Nature group members

Primarily Negative in Nature group members

Mixed Emotional in Nature group members 


\section{DATA COLLECTION FORMS: Representative Comments}

For each of the five topic areas covered in the focus group discussion, choose 2 or 3 comments made by members that represent the general feeling of the group. Write these comments under the topic headings below. Choose comments that would give someone unfamiliar with the discussions, a good idea of how the members felt about each of the topics. If opinions varied widely, choose as many comments as you feel are needed to represent the group discussion.

Bathing Habits

Bathing Preferences

Concerns About Bathing Tasks

Product Reactions 
Born, Natrona Heights, Pennsylvania

1976

$1976-1978$

$1978-1982$

1983

$1982-1989$

$1989-1991$

$1991-1992$

$1991-1995$

1992

$1992-1994$

$1993-1995$
B.A., Psychology

Indiana University of Pennsylvania

Indiana, Pennsylvania

Day Care Assistant Teacher, Miami, Florida

Research Assistant

Psychology Department, Florida International University, Miami Florida

M.A., Psychology

Florida Atlantic University

Boca Raton, Florida

Senior Research Associate

Stein Gerontological Institute, Miami Jewish Home and Hospital for the Aged

Miami, Florida

Assistant Director

Technology Center for Independent Living, Stein Gerontological Institute, Miami Jewish Home and Hospital for the Aged

Miami, Florida

Adjunct Instructor

Department of Behavioral and Social Science Central piedmont community college

Charlotte, North Carolina

Consultant

Center for Rehabilitation Technology Services South Carolina Vocational Rehabilitation

Department, Columbia, South Carolina

Elected to Phi Kappa Phi Honor Society

Florida International University Chapter

Visiting Instructor

Department of Psychology

Davidson College

Davidson, North Carolina

Assistant Professor

Department of Psychology

Queens college

Charlotte, North Carolina 


\section{PUBLICATIONS AND PRESENTATIONS}

Foos, P.W., \& Clark, M.C. (1982, March). Presentation order expected test, and test performance. Presented at the Annual Meetings of the Southeastern Psychological Association, New orleans, LA.

Levitt, M.J., \& Clark, M.C. (1982, April). Mother-infant reciprocity, causality, and response to contingent feedback. Presented at the Third Biennial International conference on Infant studies, Austin, Tx.

Foos, P.W. \& Clark, M.C. (1983). Learning from text: Effects of input order and expected test. Human Learning: Journal of Practical Research and Applications, 2, 177-185.

Clark, M.C., \& Levitt, M.J. (1983, April). Stimulus salience as a factor in the relationship between object-person permanence and quality of attachment. Presented at the Biennial Meeting of the society for Research in Child Development, Detroit, MI.

Levitt, M.J., \& Clark, M.C. (1983, April). Mother-child interaction, comprehension of emotion, and sharing behavior in toddlers. Presented at the Biennial Meeting of the society for Research in Child Development, Detroit, MI.

Levitt, M.J., Clark, M.C., Rotton, J.R. \& Finley, G.E. (1983, November). Social support and well-being in an at-risk elderly population. Presented at the 36 th Annual Meeting of the Gerontological Society of America, San Francisco, CA.

Faletti, M.V., \& Clark, M.C. (1983, November). Human factors data applied to elder-environment transactions in daily living. Presented at the 36th Annual Meeting of the Gerontological Society of America, San Francisco, CA.

Levitt, M.J., Antonucci, T.C., \& Clark, M.C. (1984). object- person permanence and attachment: Another look. Merri11-Palmer Quarterly, 30, 1-10.

Clark, M.C., Levitt, M.J., \& Finley, G.E. (1984). perceived control, social support, and non-institutional relocation of the elderly: An annotated bibliography. psychological Documents, \#2619.

Faletti, M.V., \& Clark, M.C. (1984). A capability-demand approach to the aged in technological environments: A case for improved task analysis. In P.K. 
Robinson, J. Livingston, \& J.E. Birren (Eds.), Aging and technological advances. New York, Plenum Press.

Levitt, M.J., Weber, R.A., \& Clark, M.C. (1984, April). Social support for mothers of infants: providers,

functions, and implications for maternal well-being.

Presented at the Fourth Biennial International conference on Infant Studies, New York, NY.

Weber, R.A., Levitt, M.J., \& Clark, M.C. (1984, Apri1). Maternal and infant temperament as predictors of attachment security and strange situation behavior. Presented at the Fourth Biennial International Conference on Infant studies, New York, NY.

Faletti, M.V., \& Clark, M.C. (1984, October). Task analysis in the person-robot-environment triad. Presented at The First International Robot Congress and Exhibition, Long Beach, CA.

Green, R.; Clark, M.C., \& Faletti, M.V. (1984, November). An analysis of problems encountered by elderly women in meal preparation. Presented at the 37 th Annual Meeting of the Gerontological Society of America, San Antonio, TX.

Levitt, M.J., Weber, R.A., Clark, M.C., \& McDonnell, P. (1985). Reciprocity of exchange in toddler sharing behavior. Developmental Psychology, 21, 122-123.

Clark, M.C., Gaide, M.S., Faletti, M.V., \& Weiner, W.J. (1985, March). Biomechanical assessment of chair egress in patient's with parkinson's Disease or lower limb arthritis. Presented at the First Biennial Alliance for Care Conference, Miami, FL.

Clark, M.C., Gaide, M.S., Faletti, M.V., \& Weiner, W.J. (1985, June). A biomechanical analysis of problems associated with chair egress in Parkinson's Disease. Presented at the International Parkinson's Disease Symposium, New York, NY.

Faletti, M.V., \& Clark, M.C. (1985, september). Task analysis in the human/robot environment. Presented at the Second International Personal Robot Congress and Exposition, San Francisco, CA.

Clark, M.C., \& Faletti, M.V. (1985, october). The role of seating types in egress difficulty experienced by older adults: A biomechanical analysis. Presented at the 29 th Meeting of the Human Factors Society, Baltimore, MD. 
Clark, M.C., Gaide, M.S., \& Faletti, M.V. (1985, November). Impact of arthritis-induced hand deformity on meal preparation in older women. Presented at the 38 th Annual Meeting of the Gerontological Society of America, New orleans, LA.

Levitt, M.J., Antonucci, T.C., Clark, M.C., \& Finley, G. (1985-86). Social support and well-being: Preliminary indicators based on two samples of the elderly. The International Journal of Aging and Human Development, 21 , 61-77.

Weber, R.A., Levitt, M.J., \& Clark, M.C. (1986). Individual variation in attachment security and strange situation behavior: The role of maternal and infant temperament, Child Development, 57, 56-65.

Levitt, M.J., weber, R.A., \& Clark, M.C. (1986). Social network relationships as sources of maternal support and well-being. Developmental psychology, 22, 310-316.

Clark, M.C., \& Gaide, M. S. (Fall, 1986). Choosing the right device: A capability-demand approach. Generations, 11, $18-21$.

Green, K., Silva, U., Pacheco, A., Clark, M.C., \& Faletti, M.V. (1986, March). Analysis of ADL performance of independent older adults. Presented at the Annual Meeting of the Southeastern Psychological Association, Orlando, FL.

Clark, M.C., \& Wolff, D.S. (1986, May). Robotics for the frail elderly. Invited presentation at the Technology and Aging in America conference sponsored by the Brookdale Institute on Aging and Adult Human Development at Columbia University, New York, NY.

Clark, M.C. (1986, september). The use of technology in the home by the older adult. Presented at the 30 th Annual Meeting of the Human Factors society, Dayton $\mathrm{OH}$.

Clark, M.C. (1986, November). Choosing appropriate technology: Specifying needs using a capability-demand approach. In M.C. Clark (Chair), Adaptations of technology for the elderly: A human factors perspective. A symposium presented at the 39 th Annual Meeting of the Gerontological Society of America, Chicago, IL.

Levitt, M.J., Clark, M.C., Rotton, J., \& Finley, G.E. (1987). Social support, perceived control and well-being: A study of an at-risk population. The International Journal of Aging and Human Development, 25, 249-260. 
La Buda, D.R., \& Clark, M.C. (Summer, 1987). Design that works for the aging: What's available and where to get it. Innovation, $6,15-17$.

Silva, U.A., \& Clark, M.C. (1987). Postural analysis of the elderly during grocery shopping. In S.S. Asfour (Ed.), Trends in Ergonomics/Human Factors IV. (pp 269-276). North Holland: Elsevier Science Publishers B.V.

Clark, M.C. (1987, March). Devices create demands: choosing assistive devices for the elderly. Invited presentation at The Housing Challenge Conference sponsored by the Gerontology Institute of New Jersey, Princeton, NJ.

Clark, M.C. \& La Buda, D.R. (1987, Ãpril). Ãge responsive housing: Applying human factors research on elderly performance to environmental design. Presented at the Annual Exposition of the National Association of Senior Living Industries, orlando, FL.

Clark, M.C. (1987, October). Robotics applied to daily living tasks for the elderly. In D.B. Smith (Panel Chair), Aging and technological innovation. Presented at the 31 st Annual Meeting of the Human Factors Society, New York, NY.

Benejam, A.A., La Buda, D.R., Clark, M.C., \& Weber, R.A. (1987, November). Problems encountered in daily living tasks by young and older adults. Presented at the 40 th Annual Meeting of the Gerontological society of America, Washington, D.C.

Clark, M.C., Pacheco, A. \& Aguirregaviria, A. (1988, Apri1). The role of vision and mobility in daily task performance of older adults. Presented at the Meeting of the Southeastern Psychological Association, New orleans, LA.

Clark, M.C. (1988, April). The application of basic research on task performance of older adults to recommendations for adaptable housing for the elderly. Presented at the Second Annual Meeting of the Gerontological Society of Florida, Tampa, FL.

Dol1, T.J. \& Clark, M.C. (1988, August). Task analytic approach to functional independence in the elderly. Presented at the Annual Meeting of the American Psychological Association, Atlanta, GA.

Clark, M.C. (1988, October). Today's technology in action: Living environments that promote independence: Research applications. Presented at the 27 th Annual Meeting of the American Association of Homes for the Aging, orlando, FL. 
La Buda, D.R. \& Clark, M.C. (1988, October). Encouraging independence in the long-term care setting. Presented at the 27th Annual Meeting of the American Association of Homes for the Aging, Orlando, FL.

Clark, M.C., Pacheco, A., \& Czaja, S.J. (1988, November). Task analysis of grocery shopping by older adults. Presented at the 41 st Annual Meeting of the Gerontological Society of America, San Francisco, CA.

Faletti, M.V., Gibbs, J.M., Clark, M.C., Pruchno, R.P., \& Berman, E.A. (1989). The longitudinal course of bereavement in older adults. In D. Lund (Ed.), older bereaved spouses: Research with practical applications. Washington, DC: Hemisphere Press.

Clark, M.C. (1989, Apri1). Technology in the housing environment. Invited presentation at Aging with Developmental Disabilities: A West coast Forum, Portland, OR.

Clark, M.C. (1989, Apri1). Physical environments for caregivers and alzheimer's patients. Presented at the Third Annual Gerontological Society of Florida conference, orlando, FL.

Clark, M.C. (1989, Apri1). Design and technology innovations for elders. Presented at the Third Annual Gerontological society of Florida conference, orlando, FL.

Clark, M.C. (1989, November). The use of computers to enhance social communication. Presented at the 42 nd Annual Meeting of the Gerontological society of America, Minneapolis, MN.

Clark, M.C. (1989, December). Technology transfer for the community dwelling older adult. Invited presentation at "Tomorrow is Today" - The First Regional Technology Access Conference, Little Rock, AR.

Clark, M.C., Czaja, S., \& Weber, R.A. (1990), Older adults and daily living task performance. Human Factors, $32(4), 537-549$.

Clark, M.C. (1990, March). Meeting the crisis in care: Technology to enhance independent living. Presented at the 11th Annual Meeting of the Southern Gerontological society, Orlando, FL.

Clark, M.C. (1990, Apri1). Enhancement of independent living. Presented at the 4 th Annual Meeting of the Gerontological society of Florida, Miami, FL. 
Czaja, S.J., Clark, M.C., \& Nachbar, D. (1990, october). Computer communication among older adults. Presented at the 34 th Annual Meeting of the Human Factors Society, orlando, FL.

Clark, M.C., Ravenscraft, M.T., \& Faucher, M.H. (1991, March). A model of assistive technology service delivery. Presented at the Annual Meeting of the American Society on Aging, New orleans, LA.

Clark, M.C. \& Faucher, M.H. (1991, March). Marketing assistive technology to the elderly. Presented at the 1991 Southeastern Psychological Association Conference, New orleans, LA.

Clark, M.C. (1991, May). Invited participant in "Directions 91, A Workshop on Living Environment Products for Seniors and Persons with Disabilities." Sponsored by ARCOR, held in Winnipeg, Canada, May 21 - May 24.

Clark, M.C. \& KIine, B. K. (1991, June). Assistive devices and the elderly: A shotgun wedding? Presented at the 14th Annual RESNA Conference, Kansas City, Mo.

Clark, M.C. (1992, February). Selected assistive technology for persons with cognitive impairments. In $L$. Gaster (chair), Assistive Technology Lab and Demonstrations. Panel presented at the Annual South Carolina Head Injury Conference, Columbia, SC.

Clark, M.C. (1992, March). You CAN touch this: Simulation exercises on aging and disability (SEAD). Presented at the 1992 southeastern Psychological Association conference, Knoxville, TN.

Clark, M.C. (1992, November). If you build it. will they come? Bathing needs and preferences for bathing units. Presented at the 45 th Annual Meeting of the Gerontological Society of America, Washington, DC.

Czaja, S.J., Weber, R.A., Nair, S., \& Clark, M.C. (1993). A capability-demand analysis of elderly performance. Journal of Gerontology, 48(Spec. Issue), 4450 .

Clark, M.C., Foos, P.W., \& MCQuilkin, M.E. (1993, November). The more you know the better it looks: Agespecific experience and attitudes about aging. presented at the 46 th Annual Meeting of the Gerontological society of America, New orleans, LA. 
Foos, P.W., \& Clark, M.C. (1994, April). Cultural and racial differences in attitudes about aging. presented at the Annual Meeting of the Southern Gerontological Society, Charlotte, NC.

Clark, M.C. (November, 1994). Try it you'll like it: A critique of methods used to gauge acceptance of assistive technology by older persons. Invited presentation at the Technology and Aging Special Interest Group program at the 47 th Annual Meeting of the Gerontological Society of America, Atlanta, GA.

Clark, M.C. (November, 1994). There but for the grace of God: Why some assistive technology programs work and some do not. In M.C. Clark \& R.A. Weber (Chairs) Models of assistive technology application to older populations. A symposium presented at the 47 th Annual Meeting of the Gerontological Society of America, Atlanta, GA.

Clark, M.C., Foos, P.W., Lindh, T., \& Eyles, S. (March, 1995). Attitudes toward working with individuals with disabilities. Presented at the 1995 Southeastern Psychological Association Conference, Savannah, GA. 